\title{
Removal of selected metal ions using powder of seeds of Ajwaa dates from aqueous solution
}

\begin{abstract}
At the present time, there is continuous increase of heavy metal burden in our environment, which has become one of the most serious problems globally. Heavy metals cause threat on land and in aquatic life. The problem of metals is significantly attributed by increase of activities from industrial, agricultural, hospital sectors etc. Heavy metals are not degradable, but they are persistent in environments. The aim of this study is to prepare adsorbent from powder of Ajwaa date seeds (PADS). The adsorbent was applied in removing heavy metal ion such as cadmium, lead, copper, chromium, cobalt and manganese from aqueous solution. The study also examined the removal efficiency of PADS. Constant mass of 0.1 gram of PADS which was added in a volume of $50 \mathrm{~mL}$ of ultra-pure water reached maximum removal efficiency of $93.34 \%, 71.06 \%, 92.06 \%, 96.96 \%, 95.91 \%$ and $36.13 \%$ for $\mathrm{Cd}^{2+}$ ions, $\mathrm{Cr}^{3+}$ ions, $\mathrm{Co}^{2+}$ ions, $\mathrm{Cu}^{2+}$ ions, $\mathrm{Pb}^{2+}$ ions and $\mathrm{Mn}^{2+}$ ions respectively. The findings of the present study can be taken as a best solution and baseline information of heavy metal removal in different areas. The PADS treatment is efficient, simple, low cost and green alternative for heavy metal treatments methods to overcome the problems of heavy metals discharged in aqueous solution.
\end{abstract}

Keywords: adsorbent, Ajwaa dates, cadmium, chromium, removal efficiency
Volume 8 Issue $6-2019$

\author{
Abdul Ali Juma Mohamed,' Lila Ali Vuai,' Miza \\ Kombo,' Okafor J Chukwuma² \\ 'Department of Natural Sciences, State University of Zanzibar \\ (SUZA), Zanzibar, Tanzania \\ 2Department of Pathology and Biochemistry, State University of \\ Zanzibar, Tanzania
}

\begin{abstract}
Correspondence: Abdul Ali Juma Mohamed, Department of Natural Sciences, State University of Zanzibar (SUZA), Zanzibar, Tanzania,Tel +255777 422223, Email jumabdull@yahoo.com
\end{abstract}

Received: December 22, 2019 | Published: December 31, 2019

\section{Introduction}

Toxic metals are those metals known to cause toxicity to living organisms. These metals can be either light metals or heavy metals. ${ }^{1}$ The presence of these metals in our environments is of major concern due to their toxicity, bio-accumulation, and threat to human life and environment. ${ }^{2,3}$ Toxic metals such as chromium, copper, lead, zinc, mercury, cadmium etc., are omnipresent in our environment. Possible anthropogenic sources of toxic metals in our environment include activities, such as metal cleaning and plating baths, refineries, paper and pulp, tanning, and chemical manufacturing processes. ${ }^{4}$ The toxic metals are transported by runoff water and contaminated water sources downstream from the contaminant sources. ${ }^{5}$ These metals are non-degradable and are very resistant to biodegradation. In living organisms, toxic metal ions mainly bind to nucleic acids, proteins and small metabolites. The cells biological functions are hampered as they lose their homeostatic control of essential metals, resulting in fatal health problems. ${ }^{6}$

Cadmium $(\mathrm{Cd})$ is a bluish white malleable, ductile and divalent toxic element. Cadmium is quite ubiquitous in nature. It ranges between $0.1 \mathrm{ppm}$ to $0.5 \mathrm{ppm}$. Cadmium emerged from electroplating processes and other electronics manufacturing applications. Furthermore, cadmium is also used for stabilizing poly-vinyl chloride, in television phosphors picture tube, in nickel cadmium batteries and even in controlling rods and shells in nuclear reactors. Nearly, all cadmium production in the world rises as by product of zinc smelting. ${ }^{7,8}$ This can lead to exceeding permissible limit of $3.0 \mathrm{ppb}$ according to WHO in drinking water. ${ }^{9,10}$ Cadmium and cadmium compounds are among known human carcinogens. It is believed to cause several damages to the lungs if breathed at high level, which can cause irritation to the stomach leading to vomiting and diarrhea. ${ }^{11}$ Cobalt $(\mathrm{Co})$ is a naturally occurring element in the earth crust. Plants and animals need cobalt for their function in trace amounts. The side effects of cobalt include weakening of the heart muscles (cardiomyopathy), hearing loss, vision loss, hypothyroidism, and cognitive impairment. ${ }^{12}$ Lead $(\mathrm{Pb})$ contaminant comes from industrial mining, steel, automobile, batteries, waste from science laboratory, paints and pollutants arising from increasing industrialization. It can cause nausea, encephalopathy, headache and even mental retardation. ${ }^{13}$

Manganese $(\mathrm{Mn})$ is the $12^{\text {th }}$ most abundant metal in the earth's crust. Uses of manganese include the production of medical imaging agent, dry cell batteries, fertilizer, as additive in gasoline to increase octane gas rating and in pharmaceutical product. ${ }^{14}$ Manganese is essential and it is not toxic at a trace level. It is toxic if it accumulates in excess amount with serious effect to human health including damaging of nervous system, irritation of the lungs, pneumonia, sperm count reduction, kidney and formation of kidney stones etc. ${ }^{15}$ Therefore, it is necessary to eliminate such hazardous toxic metal ions in waste water before discharging it into the ecosystem. To eliminate hazardous toxic metals there are a number of methods used in eliminating them from environment especially from drinking water source and waste water. Such methods include chemical precipitation, oxidation-reduction, solvent extraction, ion-exchange and the use of biosorbents. ${ }^{16}$ These methods, however, have merits and limitations in their applications and often is limited by technical and economic issues. The adsorption process is arguably one of the more popular methods for the removal of toxic metals ions. It is simple, convenient, and has high removal efficiency. Therefore, the use of effective materials as sorbents for metals removal from waste water has been a focus for the present study. Ajwaa dates seeds powder is capable of removing trace levels of toxic metal ions. ${ }^{17}$ As Ajwaa seeds are abundantly available, cheaper and with various functional groups (such as carboxylic acid, ester, carboxylate, hydroxyl, phenolic and amino) which can serve as adsorption sites for heavy metal ions. ${ }^{18}$ However, to improve their absorption capacity and enhance the separation rate, the design and exploration of novel adsorbents are 
still necessary. Another important point of the present research plan is that until now, there is paucity of data on the removal of toxic metals with adsorption onto Ajwaa date seeds powder (PADS). Hence the present work intends to investigate removals of toxic metals (lead, chromium, cadmium, cobalt, manganese and copper) from aqueous solution by using powder of seeds of Ajwaa dates.

\section{Materials and methods}

\section{Study sites}

The materials used in this study were prepared in Zanzibar. Nevertheless, the analysis of heavy metal contamination was done at analytical chemistry laboratory in Brunei Darussalam (UBD).

\section{Equipment and apparatus}

Inductively Coupled Plasma Optical Emission Spectrophotometer, digital weight balance, filter paper, spatula, $100 \mathrm{~mL}$ beaker, $100 \mathrm{~mL}$ conical flask, $1000 \mathrm{~mL}$ volumetric flask and funnel were used for the research.

\section{Collection of the sample}

The ICP multi-elements standard solution IV of analytical grade was used as control. The Ajwaa dates were purchased from Darajani Herbalist shop in Zanzibar. The seeds were taken out as raw materials for the powder. The pictures of the sample are shown in (Figure 1).

\section{(a)}

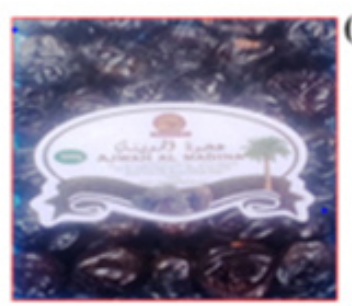

(b) 1

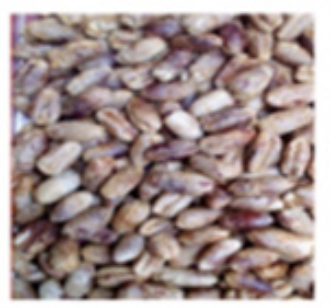

Figure I (a) Ajwaa dates (b) Ajwaa date seeds.

\section{Reagents and chemicals}

ICP multi-element standard solution IV and ultra-pure water (Figure 2)

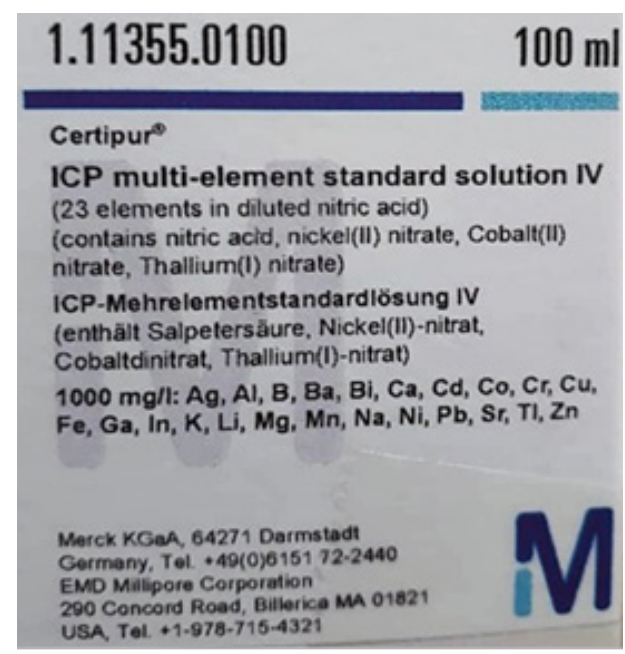

Figure 2 ICP multi-elements standard solutions.

\section{Preparation of adsorbents from Ajwaa date seeds}

Date seeds of Ajwaa dates were taken out from their original date fruits. The seeds were washed with clean rain water several times and afterwards with double distilled water. They were then dried in oven at $80^{\circ} \mathrm{C}$ for 1 hour. The dried date stones were removed from the oven. The oven temperature was adjusted to $550^{\circ} \mathrm{C}$. The Ajwaa dates seeds were inserted again and allowed to stay in the oven for an extra 1 hour at a constant temperature of $550^{\circ} \mathrm{C}$. After 60 minutes the samples were removed from the oven and transferred into a desiccators containing silica gel to prevent adsorption of air and for cooling in 1hour. After 1 hour the cooled black Ajwaa date seed samples were put in electrical grinder. The grinder was operated until very fine black powder was observed. It was then sieved using a $100 \mu \mathrm{m}$ sieve to get fine powder. The powder was put in an air tight plastic bag and stored it in cleaned desiccators.

\section{Preparation of standard reagent}

$1000 \mathrm{~mL}$ volumetric flask was cleaned, dried and labeled. A Stock standard solution containing 1000ppm of lead (ii) ion, cadmium (ii) ion, copper (ii) ion, chromium (ii) ion, cobalt (ii) iron and manganese (ii) ion by method of continuous dilution was diluted to $100 \mathrm{ppm}$. This was followed by a dilution to $10 \mathrm{ppm}$ and then finally diluted to $2 \mathrm{ppm}$. $50 \mathrm{~mL}$ of $2 \mathrm{ppm}$ of prepared standard solution was put into the flask labeled $\mathrm{S}_{3}$. They were all stored in a cool and dry place. $50 \mathrm{~mL}$ of Deionized water was used in the preparation of the above standard solution and then kept in another container labeled blank. The blank and the prepared standard solution of $2 \mathrm{ppm}$ were analyzed by Optical Inductive Coupled Plasma Spectrophotometer.

\section{Removal of heavy metal ions by $\mathbf{0 . I}$ gram of powder of Ajwaa dates seeds (PADS)}

Ten conical flasks were cleaned, dried and labeled A1, A2, A3, A4, A5, A6, A7, A8, A9, and A10. 0.1gram of PADS was added into the flask labeled A1, A2, A3, A4, A5, A6, A7, A8, A9 and A10. $50 \mathrm{~cm}^{3}$ of synthetic waste water were added into each labeled flask above containing 0.1 gram of powder of Ajwaa date seeds. The solutions in the flasks were homogenized and allowed to settle overnight. The mixtures were then filtered to get clear solutions. The analyte was put in $50 \mathrm{~mL}$ sealed container labeled A1, A2, A3, A4, A5, A6, A7, A8, A9 and A10. The filtrate was stored in a cool and dry place.

\section{The preparation of multi metal standard solution}

The multi metal standard solution was prepared, containing $0.1922 \mathrm{ppm}$ of cadmium, $0.1645 \mathrm{ppm}$ of chromium, $0.1713 \mathrm{ppm}$ of cobalt, $0.1908 \mathrm{ppm}$ of copper, $0.1956 \mathrm{ppm}$ of lead and $0.2023 \mathrm{ppm}$ of manganese. $50 \mathrm{~mL}$ of multi metal standard reagent with 0.1 gram of powder of seeds of Ajwaa date were transferred into conical flask, the mixture shaken by using rotary shaker at 200rpm and kept overnight so as to allow maximum removals. The mixture of adsorbent and adsorbate was filtered by using a filter paper. The analyte obtained was analyzed by Inductively Coupled Plasma spectrophotometer.

\section{Statistical data analysis}

The experiment was carried out at room temperature, and the analysis was carried out using ICP - OES and repeated three times, the mean values from the data were taken for Statistical analysis. The removal efficiency of selected heavy metals in terms of percentage removals were calculated in excels software by typing formula: 


$$
\% \text { removal }=\frac{C_{i}-C_{f}}{C_{i}} \times 100
$$

Where, Ci- represents initial heavy metals concentration, Cfrepresents final heavy metal concentration. Other data analysis such as maximum \% removal, minimum \% removal, mean, standard deviation and variance were done by using IBM SPSS statistics 20 version.

Table I The percentage removal efficiency of the heavy metal ions using PADS

\begin{tabular}{|c|c|c|c|c|c|}
\hline & Range & Minimum & Maximum & Mean & Std. Deviation \\
\hline [Cd]removed & 0.165 & 0.015 & 0.179 & 0.118 & 0.069 \\
\hline [Cr]removed & 0.07 & 0.047 & 0.117 & 0.076 & 0.032 \\
\hline [Co]removed & 0.114 & 0.044 & 0.158 & 0.105 & $0.05 I$ \\
\hline [Cu]removed & 0.071 & 0.114 & 0.185 & 0.159 & 0.029 \\
\hline$[\mathrm{Pb}]$ removed & 0.018 & 0.17 & 0.188 & 0.179 & 0.005 \\
\hline [Mn]removed & 0.049 & 0.024 & 0.073 & 0.052 & 0.022 \\
\hline \%Removal of [Cd] & 85.59 & 7.75 & 93.34 & 61.613 & 35.791 \\
\hline \%Removal of [Cr] & 42.37 & 28.69 & 71.06 & 46.274 & 19.595 \\
\hline \%Removal of [Co] & 66.49 & 25.57 & 92.06 & 61.407 & 29.764 \\
\hline \%Removal of [Cu] & 37.11 & 59.85 & 96.96 & 83.084 & 15.29 \\
\hline \%Removal of [Pb] & 9.2 & 86.71 & 95.91 & 91.314 & 2.699 \\
\hline \%Removal of [Mn] & 24.27 & 11.86 & 36.13 & 25.787 & 10.82 \\
\hline [Cd]equlilibrium & 0.165 & 0.013 & 0.177 & 0.074 & 0.069 \\
\hline [Co]equilibrium & 0.114 & 0.014 & 0.128 & 0.066 & 0.051 \\
\hline [Cr]equilibrium & 0.07 & 0.048 & 0.117 & 0.088 & 0.032 \\
\hline [Cu]equilibrium & 0.071 & 0.006 & 0.077 & 0.032 & 0.029 \\
\hline [Mn]equilibrium & 0.1 & 0.129 & 0.229 & 0.181 & 0.043 \\
\hline [Pb]equilibrium & 0.018 & 0.008 & 0.026 & 0.017 & 0.005 \\
\hline
\end{tabular}

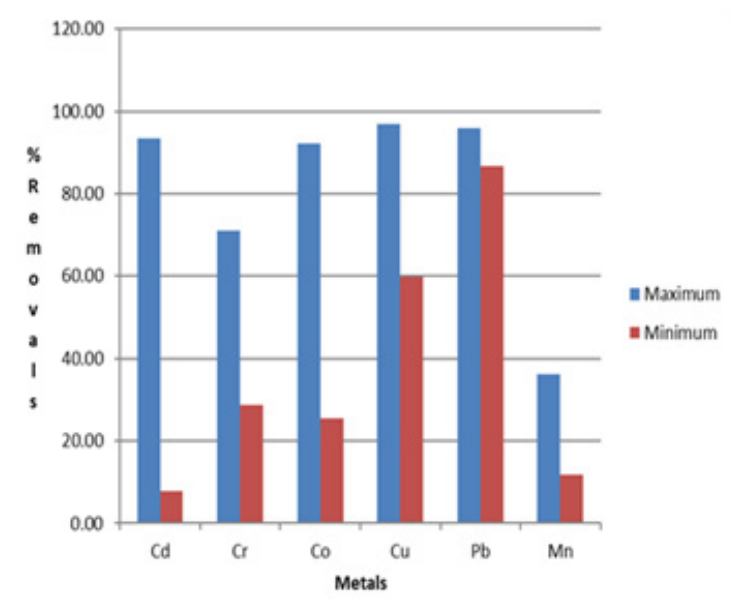

Figure 3 Maximum and minimum \% removal of heavy metal by using PADS.

\section{Results}

Table 1 The removal efficiency of the heavy metal ions using PADS. The results showed a very high removal capacity of heavy metals except for manganese. This revealed that PADS are very good adsorbent for metals ion removals from aqueous solution.

Figure 3 The maximum removal efficiency of heavy metal ions were very high except for manganese. This indicates that the metals had high bond strength to powder of ajwa date seeds except for manganese.

\section{Discussion}

Ajwa dates are very rich in nutrients including vitamins A, B, C, $\mathrm{E}$ and $\mathrm{K}$, folate, niacin, thiamin, and riboflavin. ${ }^{19,20}$ It is quite soft and juicy, moderate, good in fruit flavor, and easily chewable. Ajwa dates are the most beneficial fruits for human health. Some proven health benefits according to various research include: Improvement of the digestive health, promotion of colon health, anti-inflammatory action, reduction of blood pressure, reduced stroke risk, a healthy pregnancy and delivery, boosting of brain health, bone health, energy and stamina ${ }^{21}$ It is abundant, locally available and effective material that could be used as an adsorbent for the removal of different pollutants from aqueous solution. ${ }^{21}$

The study showed a very low level of heavy metals after treatment with powder of date seeds. This result is an indication that PADS are very goods adsorbent for metals ion removals from aqueous solution. The maximum removal efficiency of heavy metal ion was excellent 
except for manganese (ii) ion. The order of removal capacity was $\mathrm{Cu}^{2+}$ $>\mathrm{Pb}^{2+}>\mathrm{Cd}^{2+}>\mathrm{Co}^{2+}>\mathrm{Cr}^{3+}>\mathrm{Mn}^{2+}$. This finding could be attributed to the bond strengths of the various metals to ajwa date seeds. ${ }^{22}$ This does indicate that $\mathrm{Cu}^{2+}$ ion had the highest bond strength to powder of ajwa date seeds followed by $\mathrm{Pb}^{2+}$ ion, $\mathrm{Cd}^{2+}, \mathrm{Co}^{2+}, \mathrm{Cr}^{3+}$ and finally $\mathrm{Mn}^{2+}$ ion which has the lowest bond strength.

An important separation technique for toxic metals removals from effluent is adsorption, ${ }^{23}$ it can be applied to discover many tons of adsorbate materials. ${ }^{24}$ Adsorption takes place in two ways, that is, physical or chemical adsorption. Because of the stronger interactions between adsorbate and adsorbent, chemical adsorption is the most effective for toxic metals removals compared to physical adsorption. ${ }^{25}$ The functional groups on the surface of the adsorbent provide interaction sites for toxic metal removals

The relative ability of the metal species to compete for active surface sites of adsorbent PADS could be as a result of differences in electro negativity and hydrated radius of the removed heavy metals. The higher the electro negativity of a heavy metal, the larger will be its tendency to adsorb. ${ }^{26}$ Additionally, the smaller the hydrated radius of a heavy metal, the faster and quantitatively larger its adsorption over a carbon surface..$^{27}$ This means that those with high electro negativity and small hydrated radius were highly removed compared to the others. Experimental and model results by some researchers suggested that date seed-derived bio char has high adsorption capacity for $\mathrm{Pb}[\mathrm{II}]$ compared to other plant-based biochars. ${ }^{28}$

There is paucity of data as well as research on the use of date seed powders as adsorbents for heavy metals. Most research had concentrated on the use of date stones instead of powders as potential adsorbents. Some workers, ${ }^{29}$ who fed different doses of date palm seed on some species of fresh water fish recorded a significant decrease on the heavy metal concentrations of the fishes. They therefore concluded that feeding common carp a diet enriched with date palm seed extract could decrease heavy metal concentration that can cause cancer. Other researchers ${ }^{[30]}$ tested the adsorption of targeted heavy metals by raw date pits and burnt date pits. The result showed that burnt date pits were more efficient as adsorbents and mostly adsorbing $\mathrm{Cu}(\mathrm{II})$. They attributed the enhanced removal efficiency to the increased area of the adsorbent surface made possible by the burning of the date seeds. This very high rate of $\mathrm{Cu}(\mathrm{II})$ adsorption was equally demonstrated in our study. The high removal efficiency of carbonized date seeds for the removal of heavy metals $\mathrm{Cu}(\mathrm{II})$ from industrial waste water collected from tannery had also been demonstrated by another group of workers [31]. Some workers, ${ }^{27}$ considered the order of heavy metals adsorption on dates pits adsorption carbon to be $\mathrm{Pb}$ (II) $>\mathrm{Cu}$ (II) $>\mathrm{Cd}$ (II) $>\mathrm{Zn}$ (II) This result was not too different from our findings. The nature and design of the prepared date stones could have accounted for the slight difference. Additionally, the observed equilibrium means, and standard deviation demonstrated excellent fitness of the used adsorbent for heavy metals removal except for manganese.

\section{Conclusion}

The powder of Ajwaa date seeds (PADS) had been converted into adsorbent and successfully applied in this study as a cheap and effective adsorbent for the recovering of copper (ii) ions, lead (ii) ions cadmium (ii) ions, cobalt (ii) ions, chromium (iii) ions and manganese (ii) ions from aqueous solution. The removal experimental study and mechanisms also depend on various factors such as initial metal ion concentration, competition of metal-metal ions to the binding sites, temperature, properties of metals ions, the size of ions and solubility of metals ions. The results of the study showed that the adsorption efficiency of PADS was remarkably high. The maximum metal ions removals efficiency using PADS were very high for most of the metals except manganese. It is therefore plausible that with the high adsorption efficiency, adsorbent (PADS) can be used to remove metal ions from aqueous solution.

\section{Acknowledgments}

None.

\section{Conflicts of interest}

The author declares that there are no conflicts of interest.

\section{Funding}

None.

\section{References}

1. Wilson, K, Chung W Seo, Wayne E Marshall, et al. Selected metal adsorption by activated carbon made from peanut shells. Biotechnology. 2005;97(18):2266-2290.

2. Kaur A, Sharma S. Removal of heavy metals from wastewater by using various adsorbents: A review. Indian journal of science and technology. $2017 ; 10(34)$

3. Sparks D. Toxic metals in the environment: the role of surfaces development of plant and soil science. University of Delaware: 2005;1:193-197.

4. Sing $\mathrm{H}$ et al. Review on sources and effect of heavy metal in soil: it's Bioremediation. International journal of research applied natural and social science. 2018;22:2345-4550.

5. Lakherwal D. Adsorption of heavy metals: A review. International journal of environmental research and development. 2014;4(1):41-48.

6. Farghali AA, Mohamed Bahgat, $\mathrm{MH}$ Khedr, et al. Adsorption of $\mathrm{Pb}^{2+}$ ions from aqueous solutions using copper oxide nanostructures. Journal of basic and applied science. 2013;61(6):61-71.

7. Brown S, Chaney R, Hallfrisch J, et al. In situ soil treatments to reduce the Phyto and bioavailability of lead, zinc and cadmium. Journal of environmental quality. 2004;33(2):522-531.

8. Anetor JI. Rising environmental cadmium levels in developing countries: Threat to Genome stability and health. Niger J Physiol Sci. 2012;27(2):103-115

9. WHO. Preventing disease through health environments. Geneva: Public health and environment. 2010

10. Naurot T, Staessen JA, Roels HA, et al. Cadmium exposure in the population from health risks to strategies of prevension. Biometals. 2010;23(5):769-782.

11. Eissa FI. Protective effects on ascorbic acid and zinc against cadmium induced histopathological, histochemical and cytogenetic changes in rates. Cominicata scientiae. 2012;3(3):162-80.

12. Smith IC, Carson BL. Volume 6-Cobalt An Appraisal of Environmental Exposure. Ann Arbor: Ann Arbor Science. 1981.

13. Jain RN, S. B. Patil, D. S. Lal, et al. Adsorption of Cr (iv) from aqueous environment using neem leaves powder. International journal research in engineering and technology. 2014;3:2321-7308.

14. Aschner M, Erikson K. Manganese. Advanced in Nutrition. 2017;8(3):520-521. 
15. Zheng W, Neal O. Manganese toxicity upon over exposure: a decade in review. Curr environmental rept. 2015;2(3):315-328.

16. Zwain HM, Mohammadtaghi Vakili, Irvan Dahlan. Waste material adsorbents for zinc removal from wastewater, A comprehensive review. Journal of chemical engineering. 2014;1:1-13.

17. Bilal M, Hajira Haroon, Qaisar Mahmood, et al. Waste water biomass adsorbent for copper removals from industrial west. Journal of hazardous material. 2013;263(2):322-333.

18. Holai H. Removal of heavy metals using nanostructured graphite oxide, silica nanoparticles and silica/ graphite oxide composite. Energy procedia. 2014;50:130-138.

19. Ahmed RR. Antioxidant and tissue protective studies on ajwa extract dates from Almadinah Monawarah, Saudiarabia. Journal of environment \& analytical toxicology. 2013;3(1):163.

20. Taugeer HM, Qadir MI, Ali M, et al. Review on ajwa date Phoenix dactylifera: An emerging plant in Pharmaceuticological research. Journal of pharmaceutical science. 2014, 27(3):607-661.

21. Khalid, Nauman Khalid, Rao Sanaullah Khan, et al. A review on chemistry and Pharmacology of ajwa date fruit and pit. Trend in food science \& Technology. 2017;63:60-69.

22. Imtithal SH, Ahmad Kabbani, Hanafy Holail. Removals of heavy metals using nanostructured graphite oxide, silica nanoparticles and silica/ graphite oxide composite. Technology and materials for renewable energy, environment and sustainability. 2014;50:130-138.

23. Muharrem I, Olcay KI. An overview of adsorption techniques for heavy metal removal from wastewater. Inc journal pure applied science. 2017;3(2):10-19.
24. Barakat MA. New trends in removing heavy metals from industrial wastewater. Arabian journal of chemistry. 2011;4(4):361-377.

25. Huang Y. Application of polyvinyl amine in removal of heavy metals from wastewater by polymer enhanced ultrafiltration and adsorption. Yifeng Huang. 2016;158:124-136.

26. Alsohaimi IH, Mohammad Wabaidura, Mahendra Kumar, et al, Synthesis, characterization of PMDA/TMSPEDA hybridnano-composite and its applications as an adsorbent for the removal of bivalent heavy metals ions. Chem Engl J. 2015;270:9-21.

27. Aldawsari A, Moonis Ali Khan, BH Hameed, et al. Mercerized mesoporous date pit activated carbon-A novel adsorbent to sequester potentially toxic divalent heavy metals from water. PLOSONE. 2017;12(9):e0184493.

28. Mahdi, Z. et al. Removal of lead (II) from aqueous solution using date seed-derived biochar: batch and column studies. Applied Water Science. 2018;8:1-13.

29. Maryam Mohammadi, Mehdi Soltani, Amir Siahpoosh, et al. Effects of Date Palm (Phoenix dactylifera) Seed Extract on Heavy Metals Concentrations in Carp (Cyprinus carpio). Pol $J$ Environ Stud. 2016;25(3):1117-1123.

30. Khalid Al-Saad, El-Azazy M, Issa AA, et al. Recycling of Date Pits into a Green Adsorbent for Removal of Heavy Metals: A Fractional Factorial Design-Based Approach. Front Chem. 2019;7:552.

31. Arshad, et al., Adsorption of Heavy Metals from Industrial Wastewater using Palm Date Pits as Low-Cost Adsorbent. International Journal of Engineering and Advanced Technology (IJEAT). 2014; 3(5). 